\title{
An Analysis of Anthropometric Indicators and Modifiable Lifestyle Parameters Associated with Hypertensive Nephropathy
}

\author{
Christiana Aryee, ${ }^{1,2}$ William K. B. A. Owiredu, ${ }^{1,3}$ James Osei-Yeboah, ${ }^{1,4}$ \\ Ellis Owusu-Dabo, ${ }^{5,6}$ Edwin F. Laing, ${ }^{1,3}$ and Isaac K. Owusu ${ }^{7}$ \\ ${ }^{1}$ Department of Molecular Medicine, School of Medical Sciences, Kwame Nkrumah University of Science and Technology, \\ Kumasi, Ghana \\ ${ }^{2}$ Becton Dickinson Biosciences Technical Services, West Africa, Accra, Ghana \\ ${ }^{3}$ Department of Clinical Biochemistry, Diagnostic Directorate, Komfo Anokye Teaching Hospital, Kumasi, Ghana \\ ${ }^{4}$ Department of Medical Laboratory Sciences, School of Allied Health Sciences, University of Health and Allied Sciences, Ho, Ghana \\ ${ }^{5}$ School of Public Health, Kwame Nkrumah University of Science and Technology, Kumasi, Ghana \\ ${ }^{6}$ Kumasi Centre for Collaborative Research in Tropical Medicine, Kwame Nkrumah University of Science and Technology, \\ Kumasi, Ghana \\ ${ }^{7}$ Department of Medicine, School of Medical Sciences, Kwame Nkrumah University of Science and Technology and \\ Komfo Anokye Teaching Hospital, Kumasi, Ghana
}

Correspondence should be addressed to William K. B. A. Owiredu; wkbaowiredu@yahoo.com

Received 27 May 2016; Revised 15 August 2016; Accepted 18 August 2016

Academic Editor: Tomohiro Katsuya

Copyright ( $(2016$ Christiana Aryee et al. This is an open access article distributed under the Creative Commons Attribution License, which permits unrestricted use, distribution, and reproduction in any medium, provided the original work is properly cited.

\begin{abstract}
The surge in prevalence of chronic noncommunicable diseases like hypertension and chronic kidney disease has been linked with modifiable lifestyle practices and increased body fat. This study sought to compare the association between different modifiable lifestyle practices, adiposity indices, renal function parameters, and hypertension as well as the predictive implications for levels of these parameters in target cardiac organ damage among an urban Ghanaian hypertensive population. Using a hospital-based casecontrol study design, 241 Ghanaian indigenes from the Kumasi metropolis were recruited for this study. The case group was made up of 180 hypertensives and 61 normotensives served as controls. In addition to sociodemographic data, standard haemodynamic, anthropometric, renal function, and cardiac organ damage assessments were done. The prevalence of chronic kidney disease (CKD) ranged from $13.3 \%$ to $16.6 \%$ depending on the equation used in estimating the glomerular filtration rate (eGFR). Percentage cluster distribution by chronic kidney disease was observed to be significantly tilted toward the upper quartiles (3rd and 4th) of the haemodynamic parameters measured. Chronic kidney disease was significantly higher among self-reported smokers and alcoholic hypertensives. In this urban population, adiposity was associated with hypertension and renal insufficiency. Chronic kidney disease was associated with hypertension and cardiac abnormalities.
\end{abstract}

\section{Background}

High blood pressure is a major health problem all over the world [1]. Ghana and other countries in Sub-Saharan Africa (SSA) are experiencing an epidemic of cardiovascular diseases propelled by rapidly increasing rates of hypertension
[2]. A reciprocal or bidirectional relationship has been postulated for hypertension and end-stage chronic kidney disease (ESCKD) [3]. Hypertension is a key pathogenic factor linked to deterioration of kidney function, whilst the most common forms of secondary hypertension are attributable to chronic kidney disease [4-6]. According to Commodore-Mensah 
et al. [7], hypertension is the leading cause of renal failure in Ghana, whilst Owiredu et al. [8] estimated a 20-fold higher increased risk of death through cardiovascular complications among chronic kidney disease (CKD) patients than any other cause in the general population.

The upsurge in chronic noncommunicable diseases has been attributed to modifiable lifestyle practices characterized by sedentary lifestyle and a resultant obesity [9-13]. Evidence that hypertension is related to increases in body fat is well established in the literature [14-22]. Epidemiological studies of the impact of obesity on outcome in chronic kidney disease (CKD) remain conflicting, with several well-designed studies even suggesting a survival advantage for obese end-stage renal disease (ESRD) patients [23-25].

This study sought to compare the association between different modifiable lifestyle practices, adiposity indices, renal function parameters, and hypertension as well as the predictive implications for levels of these parameters in target cardiac organ damage among an urban Ghanaian hypertensive population.

\section{Material and Methods}

2.1. Study Participants. A hospital-based case-control study was conducted between November 2012 and September 2013. Two hundred and forty-one participants were involved in this study. One hundred and eighty (108) nondiabetic hypertensive patients were attending clinic at the Komfo Anokye Teaching Hospital (KATH) and the Precise Specialist Clinic, all in Kumasi, Ghana, and sixty-one (61) age-matched normotensive controls were from the Kumasi metropolis. The study participants were recruited from a population of adult individuals between the ages of 22 and 87 years. Criteria for the case group were patients diagnosed with hypertension who were not suffering from diabetes and were of consent age. The control group were normotensive agematched healthy individuals with no past history of diabetes, cardiac, renal, and hepatic dysfunction, or dyslipidaemia, living in the Kumasi metropolis, who consented to participate in this study. The detailed characteristics of study participants have been published in an earlier work [26].

2.2. Sociodemographic Data Capture (Questionnaire). Selfreported structured questionnaire was administered to determine duration of hypertension and treatment status, smoking status, alcohol intake, educational level, physical activity levels, occupation, the usage of nonprescribed orthodox and herbal medications, family history of hypertension, current and past symptoms of cerebrovascular disease, and peripheral vascular and coronary heart diseases.

2.3. Blood Pressure (BP) Measurement. Blood pressure (BP) and pulse rate measurements were done using the Omron M5-I digital fully automatic blood pressure monitor (OMRON Healthcare Europe BV Wegalaan 57 NL-2132 JD Hoofddorp). After participants had sat quietly for at least ten minutes, three measurements were taken at one-minute intervals on the right arm in a seated position, with arm supported at heart level and feet flat on the floor using an appropriate sized cuff. Hypertension was diagnosed when the mean of the second and third blood pressure (BP) measurements was equal or above $140 / 90 \mathrm{mmHg}$ or when participants reported use of antihypertensive medication which was verified from their hospital files [27, 28].

2.4. Anthropometric Variables. Anthropometric measurements included height to the nearest millimeter without shoes and weight to the nearest $0.1 \mathrm{~kg}$ in light clothing. Subjects were weighed on a bathroom scale (Zhongshan Camry Electronic Co. Ltd., Guangdong, China) and their height was measured with a Seca stadiometer with the participant standing erect with back straight, heels together, and feet slightly apart at a 60-degree angle. Waist circumference (to the nearest centimeter) was measured with a Gulick II springloaded measuring tape (Gay Mills, WI) midway between the inferior angles of the ribs and the suprailiac crests. The hip circumference was measured as the maximal circumference over the hip circumference (HC) at the level of the widest diameter around the gluteal protuberance in centimeters. Body mass index (BMI) was calculated by dividing weight (kg) by height squared $\left(\mathrm{m}^{2}\right)$. The waist-to-hip ratio (WHR) was calculated by dividing the waist circumference $(\mathrm{cm})$ by the hip circumference $(\mathrm{cm})$. Waist-to-height ratio was calculated by dividing the waist circumference $(\mathrm{cm})$ by the height circumference $(\mathrm{cm})$. Other calculated adiposity indices were as follows:

(1) Conicity index (CI) [29]:

$$
\mathrm{CI}=\frac{\text { Waist Circumference }(\mathrm{m})}{[0.109 \times \sqrt{\text { Weight }(\mathrm{Kg}) / \text { Height }(\mathrm{m})}]}
$$

(2) Abdominal volume index (AVI) [30]:

AVI

$=\frac{\left[2(\text { Waist } \mathrm{C}(\mathrm{cm}))^{2}+0.7\{\text { Waist } \mathrm{C}(\mathrm{cm})-\text { Hip C }(\mathrm{cm})\}^{2}\right]}{1000}$

(3) Body Adiposity Index (BAI) [31]:

$$
\text { BAI }=\frac{\text { Hip Circumference }(\mathrm{cm})}{[\text { Height }(\mathrm{m})]^{1.5}}-18 .
$$

2.5. Biochemical Assays. Venous blood samples were collected after an overnight fast (12-16 hours) between 7 am and $10 \mathrm{am}$. About $5 \mathrm{~mL}$ of venous blood was drawn from the antecubital vein of which four $\mathrm{mL}$ was dispensed into vacutainer ${ }^{\circledR}$ plain tubes and one $\mathrm{mL}$ was dispensed into fluoride oxalate tubes. After centrifugation at $500 \times \mathrm{g}$ for 15 minutes, the serum and plasma were stored at $-80^{\circ} \mathrm{C}$ until assayed. Parameters that were determined include fasting blood glucose (FBG) to exclude participants with diabetes, urea, creatinine, uric acid, potassium, sodium, and chloride. The methods adopted for the determination of the urea, creatinine, and uric acid were predetermined by the reagent manufacturer (Dialab GmbH, IZ-NÖ Süd, Hondastrasse, A-2351 Wiener Neudorf, 
Austria). Ion Selective Electrode (ISE) method was used to assay electrolytes (AVL 9180 Electrolyte Analyzer, Roche Diagnostics, Switzerland, http://www.roche.com/index.htm) at the Komfo Anokye Teaching Hospital in Kumasi. All other biochemical analytical investigations were carried out at the Kumasi Centre for Collaborative Research in Tropical Medicine (KCCR) located at the Kwame Nkrumah University of Science and Technology, Kumasi.

2.6. Clinical Assessment. All the 241 participants underwent clinical assessment to determine target organ damage. Detailed history, physical examination, chest X-ray, 12-lead resting electrocardiogram (ECG), and transthoracic echocardiogram (ECHO) were done. All diagnoses and interpretation were performed by consultant radiologists and cardiologists.

2.7. Diagnosis of Chronic Kidney Disease. Estimate glomerular filtration rate (GFR) was calculated from serum creatinine according to Cockcroft-Gault (CG) equation as follows:

$$
\text { eGFR }=\frac{(140-\text { Age }) \times \text { Weight }}{72 \times \text { Serum Creatinine }}(\times 0.85 \text { if female }) .
$$

\subsection{Four-Variable Modification of Diet in Renal Disease.}

$$
\begin{aligned}
\mathrm{eGFR}= & 186 \times \mathrm{SCr}^{-1.154} \times \mathrm{Age}^{-0.203} \\
& \times(1.212) \times(0.742 \text { if female })
\end{aligned}
$$

$(4 \mathrm{v}-\mathrm{MDRD})$

The eGFR results from the various renal function equations were used to stratify the study population into five categories corresponding to the five stages of CKD in the K/DOQI CKD classification [32]. Chronic kidney disease was classified as eGFR $<60 \mathrm{~mL} / \mathrm{min} / 1.73 \mathrm{~m}^{2}$ (stages 3, 4 and 5; see Table 5) [33].

2.9. Diagnosis of Heart Failure. Heart failure was diagnosed, using the modified Framingham criteria for diagnosis of heart failure [34]. Major criteria included paroxysmal nocturnal dyspnea, raised jugular venous pressure, cardiomegaly, basal crepitation, S3 gallop, and acute pulmonary oedema. Minor criteria included tachycardia, orthopnea, exertional dyspnea, nocturnal cough, hepatomegaly, and diuretic use. Heart failure was diagnosed if the participant had two major and one minor or one major and two minor criteria. Other complications of hypertension included cardiomegaly (without heart failure), stroke or transient ischaemic attack, and chronic kidney disease.

2.10. Statistical Analysis. Normality of all continuous variables was tested. All nonparametric variables were normalized by log transformation before analysis. Results obtained after analysis of log transformed variables were converted by antilog. Continuous variables were expressed as their mean \pm SEM, whereas categorical variables were presented as count and proportion. Comparisons of the general characteristics of the hypertensive group against the normotensive group were performed using unpaired $t$-tests, chi square $\left(\chi^{2}\right)$ tests, or Fisher exact tests where appropriate. Analysis of variance (ANOVA) and Bonferroni post hoc test were used to compare more than two means, whilst a post hoc linear contrast test was used for trend analysis of continuous variables. A level of $p<0.05$ was considered as statistically significant for all analyses. IBM Statistical Package for the Social Sciences (SPSS Inc., Chicago, USA (http://www.spss.com) version 20.00) and GraphPad Prism version 6.00 GraphPad software, San Diego, California, USA (http://www.graphpad.com/), for windows were used for statistical analysis where appropriate.

\section{Results}

Two hundred and forty-one (241) adult Ghanaians were recruited for the study. The sociodemographic characteristics of the participants, as shown in Table 2, involved 61 (25.3\%) normotensives and $180(74.7 \%)$ hypertensives, of which 40 patients representing $16.6 \%$ of the study population were newly diagnosed hypertensives who were not on any hypertensive drugs and were classified as drug-naive. Female participation was higher in each of the three categories of subjects. The informal sector employees dominated the case group. Significantly self-reported alcohol intake and smoking were both found to be more prevalent among the hypertensives, peaking in each case in the drug-naive group. No significant differences were recorded in the rest of the sociodemographic parameters assessed between the three different groups of participants evaluated in this study (see Table 2).

Among all the parameters evaluated as shown in Table 3, no statistically significant variation was recorded between the newly diagnosed hypertensives and their counterparts on treatment. Higher anthropometric indices were recorded among both hypertension groups compared with the normotensives; however, in the case of body mass index (BMI) and waist-to-hip ratio (WHR) the difference was not statistically significant. The hypertensives presented with significantly higher mean serum biochemical indices of renal dysfunction and electrolytes levels than their normotensive counterparts. The average concentration of microalbumin excreted in the urine as well as the glomerular filtration rate estimated by both ( $4 \mathrm{v}-\mathrm{MDRD})$ and (CG) equations was comparable among the treatment-naive hypertensives and the normotensives (see Table 3 ).

Among the general study population after adjusting for age and gender, positive additive changes in waist-toheight ratio (WHtR) as well as both the abdominal body frame factors (waist circumference (WC); hip circumference (HC)), the abdominal body region volumetric models for central obesity (conicity index (CI); abdominal volume index (AVI)) and body fat deposition (body adiposity index (BAI)) were associated with corresponding incremental changes in the haemodynamic measures (hypertension), the serum biochemical kidney profile measures, and renal insufficiency (decreasing eGFR). Among the hypertensive subpopulation, positive association was observed between the anthropometric measures and the serum biochemical kidney profile $\left(\mathrm{K}^{+}, \mathrm{Na}^{+}, \mathrm{Cl}^{-}\right.$, urea, creatinine, and UA) as well as renal 


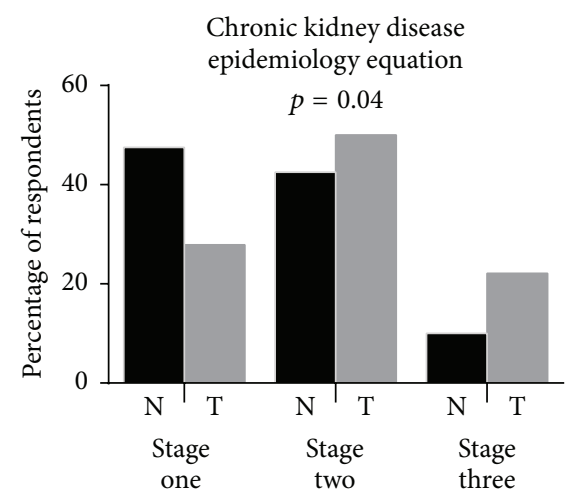

(a)

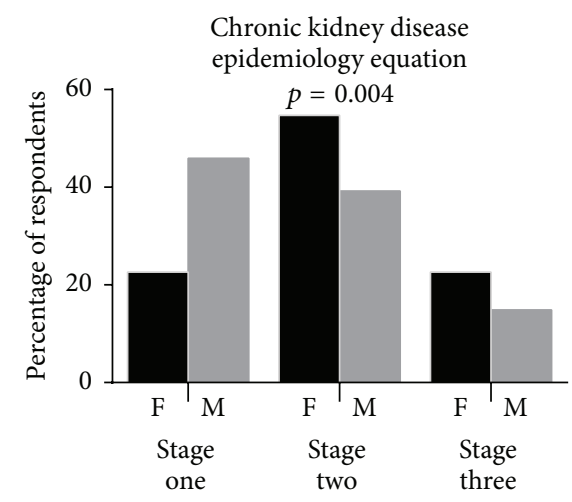

(d)

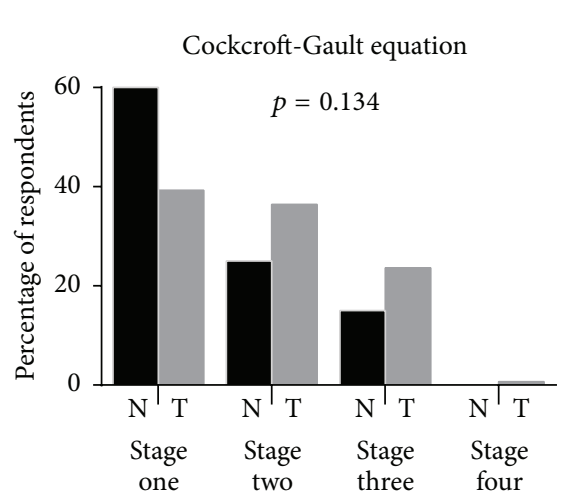

(b)

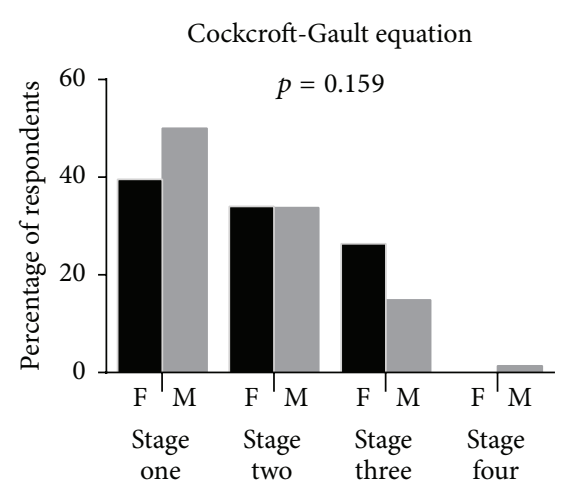

(e)

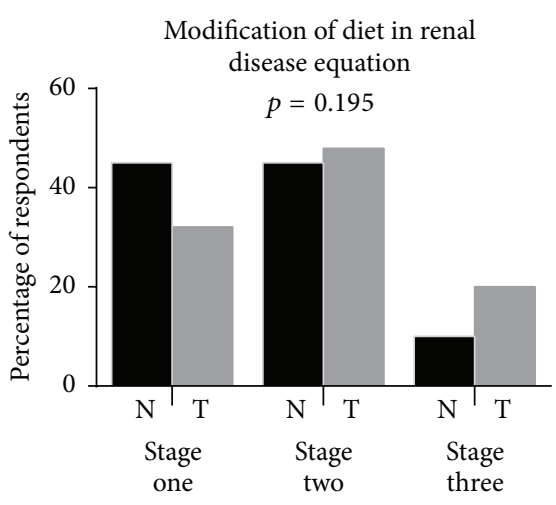

(c)

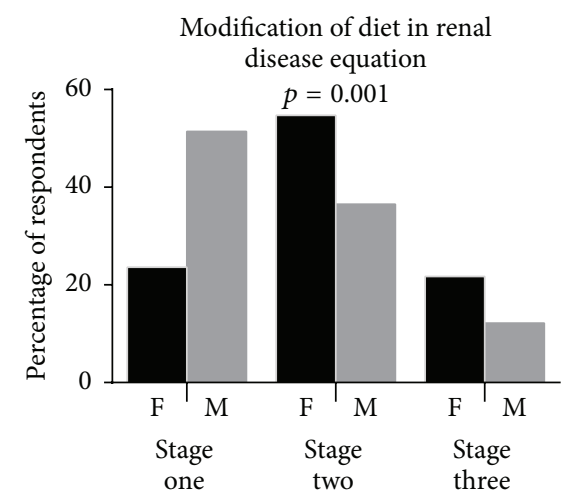

(f)

FIGURE 1: Estimates of the prevalence of CKD in the study population using the renal function equations stratified by therapy and gender. N: drug naïve, T: therapy, F: female, and M: male.

insufficiency. With the exception of pulse, no significant correlation was observed between the anthropometric measures and the haemodynamic measures among the hypertensive subpopulation.

Among both the general study population and the hypertension subgroup increasing levels of serum potassium, urea, creatinine, and uric acid were associated with increasing renal insufficiency. Significant association between the haemodynamic measures and the serum biochemical kidney profile was more profound in the general study population than the hypertension subgroup (see Table 4).

Among the total population of 241 participants, $13.3 \%$ presented with chronic kidney disease (CKD) when assessed by the four-variable modification of diet in renal disease (4v-MDRD) equation. The Cockcroft-Gault (CG) recorded $16.6 \%$ and the chronic kidney disease epidemiology collaboration (CKD-EPI) equation recorded 14.5\%. All patients presenting with CKD belong to the hypertension group. With the exception of one study participant who was observed to be in stage four by the Cockcroft-Gault (CG) equation, all CKD patients observed were in the third stage (see Table 5).

Among the hypertensive patients who were newly diagnosed and thus treatment-naive and those who were on therapy irrespective of the equation used in assessing glomerular filtration rate, the group on therapy recorded a greater percentage of end-stage chronic kidney disease (CKD) than their naïve counterparts; however, with the exception of the chronic kidney disease epidemiology collaboration (CKDEPI) equation (see Figure 1(a)), this difference was not statistically significant (see Figures $1(\mathrm{a})$ and $1(\mathrm{c})$ ). With the exception of the Cockcroft-Gault (CG) equation (see Figure 1(e)), significant gender differences in the incidence of CKD were observed. Using the CKD-EPI equation, $22.6 \%$ of hypertensive females presented with CKD compared to $14.9 \%$ of hypertensive males (see Figure 1(d)). Twenty-one and seven percent $(21.7 \%$ ) of females compared to $12.2 \%$ of males presented with CKD as per the four-variable modification of diet in renal disease (4v-MDRD) equation (see Figure 1(f)).

Irrespective of the equation used in estimating the glomerular filtration rate (GFR), self-reported nonalcoholics presented with significantly higher percentage of chronic kidney disease (CKD) than the alcoholics $(23.6 \%$ versus $16.7 \%$; $30.6 \%$ versus $16.7 \%$; and $20.8 \%$ versus 15.7 ) for chronic kidney disease epidemiology collaboration (CKD-EPI), CockcroftGault (CG), and four-variable modification of diet in renal disease (4v-MDRD) equations, respectively.

From Figure 2(d), significantly higher percentage of smokers (37.9\%) were observed with CKD, compared to their counterparts who did not smoke (15.9\%), a similar outcome was observed with the use of (4v-MDRD) where (37.9\%) of smokers presented with CKD compared to (13.9\%) of nonsmokers (see Figure 2). 


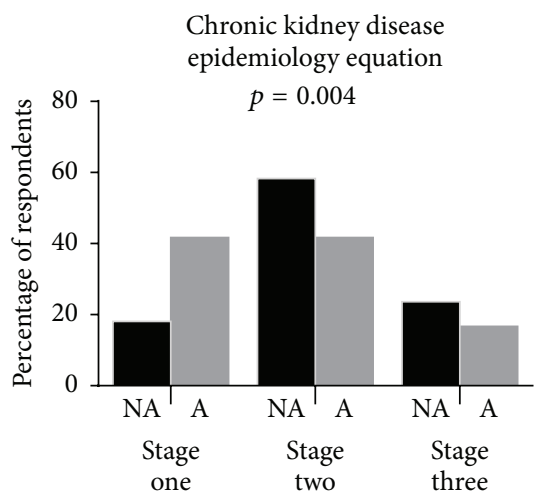

(a)

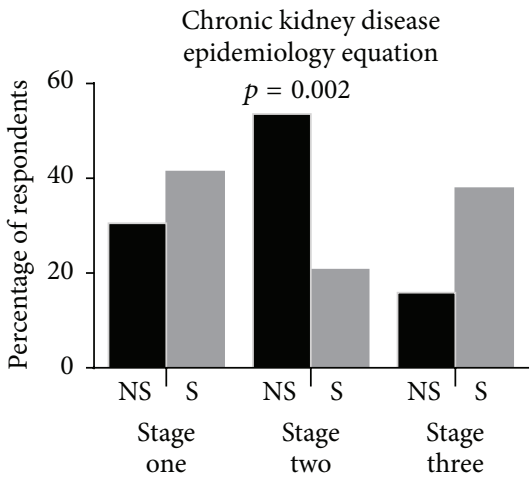

(d)

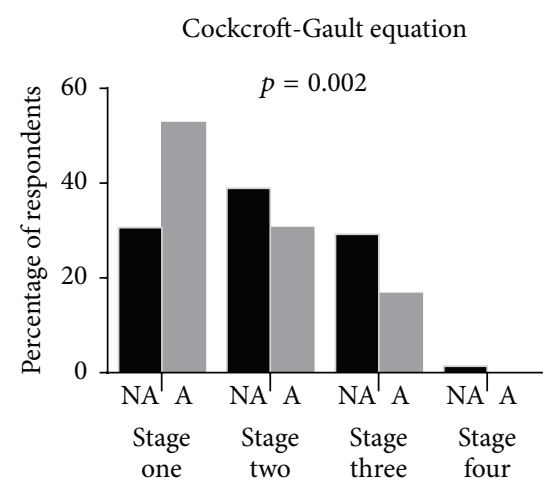

(b)

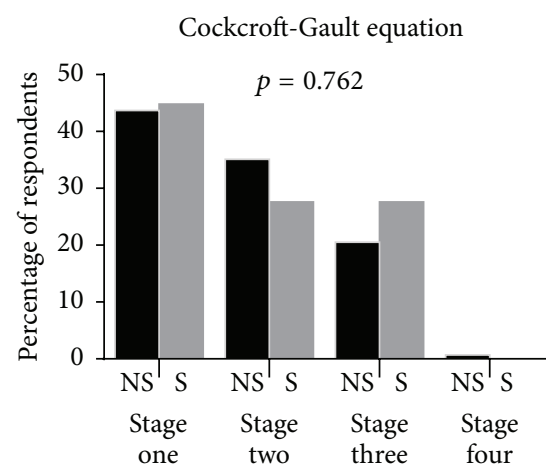

(e)

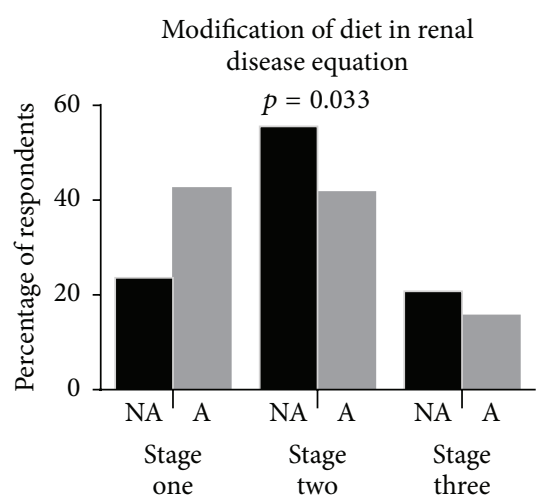

(c)

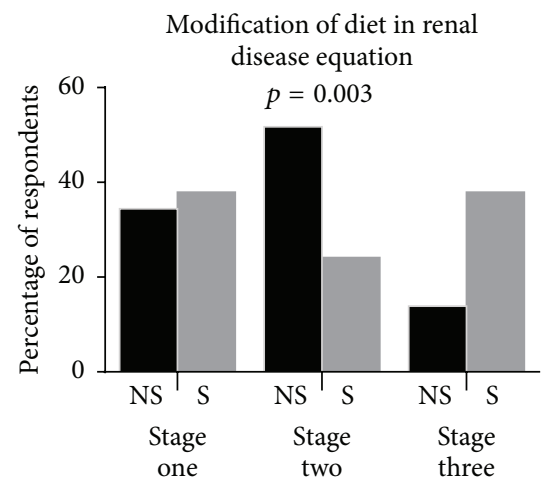

(f)

FIGURE 2: Estimates of the prevalence of CKD in the study population using the renal function equations stratified by alcohol consumption and smoking status. NA: nonalcoholic, A: alcoholic, S: smoker, and NS: nonsmoker.

Almost all participants presenting with chronic kidney disease (CKD) clustered at the upper quartiles (3rd and 4th) of systolic blood pressure. The exception included $10 \%$ of CKD subjects who clustered at the lower quartiles $(7.5 \%$ and $2.5 \%$ for 1st and 2nd quartiles, resp.) of systolic blood pressure when Cockcroft-Gault (CG) equation was used to estimate the glomerular filtration rate. Percentage cluster distribution by CKD was observed to be significantly tilted toward the upper quartiles of diastolic blood pressure. Though not statistically significant, the majority of CKD participants clustered in the third and fourth quartiles of pulse, irrespective of the renal function equation used. The majority of participants presenting with microalbuminuria clustered in the upper quartiles of the haemodynamic parameters evaluated (see Figure 3).

The prevalence of microalbuminuria among the alcoholic subjects was $32.4 \%$ compared to $27.8 \%$ among the nonalcoholics. Study participants who smoked recorded a higher percentage of microalbuminuria compared to nonsmokers and also a higher number of smokers were found to cluster at increasing levels of microalbuminuria compared to nonsmokers. Patients using herbal medicine had higher microalbuminuria (32.7\%) than those who were not using herbal medications (27.6\%). Even though higher microalbuminuria was observed among the physically active group, severity of microalbuminuria was more profound in their nonactive counterparts (see Figure 4).
In general, significant additive linear relationship was observed for all serum renal biochemical parameters assayed with progressive quartile increment of haemodynamic indices. The exception was observed with the average levels of uric acid among the diastolic quartile cluster distribution, where no significant linearity was observed.

Irrespective of the renal function equation used in the estimation of the glomerular filtration rate among the study population, participants presenting with cardiac abnormalities (left ventricular hypertrophy-electrocardiograph, left ventricular hypertrophy-echocardiograph, and cardiomegaly-X-ray) recorded significant prevalence of chronic kidney disease compared to their counterparts who were without the specific abnormal heart condition (see Table 6).

\section{Discussion}

Earlier reports by Addo et al. [35] and Osafo et al. [36] put the calculated incidence of renal insufficiency (eGFR < $60 \mathrm{~mL} / \mathrm{min} / 1.73 \mathrm{~m}^{2}$; stages 3, 4, and 5) among different hypertensive populations in Accra Ghana at $4.1 \%$ and $27.8 \%$, respectively. The estimates of hypertensive kidney target organ damage burden for the present study $(17.80 \%-22.22 \%)$ compared to the earlier records in the previous studies but were higher than the former and lower than the latter. The difference in CKD burden for the hypertensive cohort 


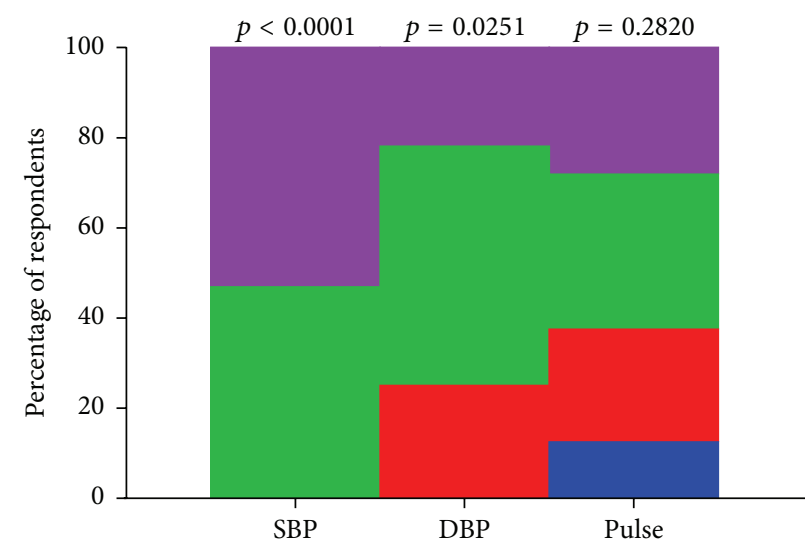

Chronic kidney disease by $4 \mathrm{v}-\mathrm{MDRD}$ equation

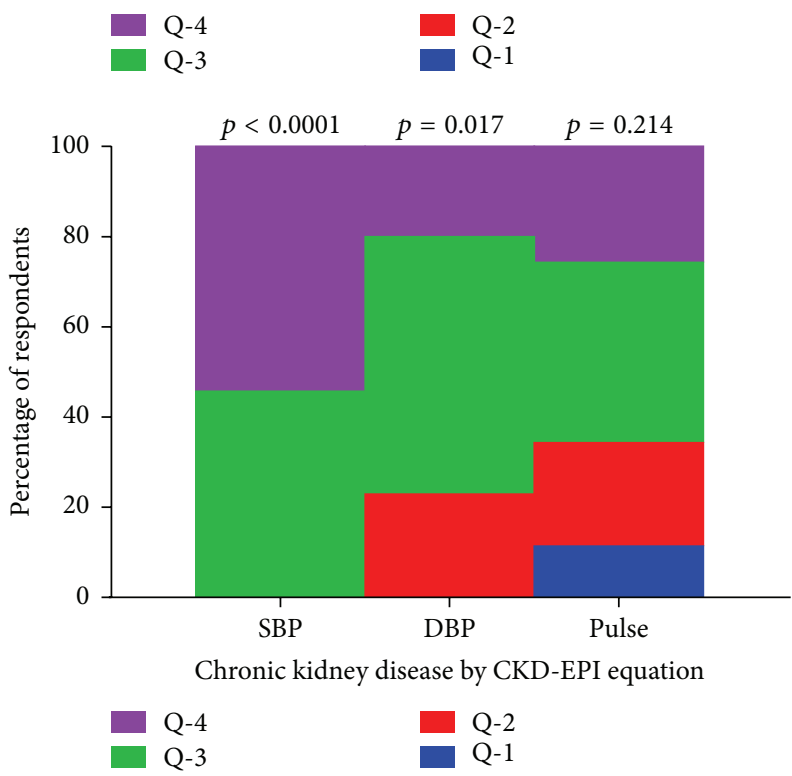

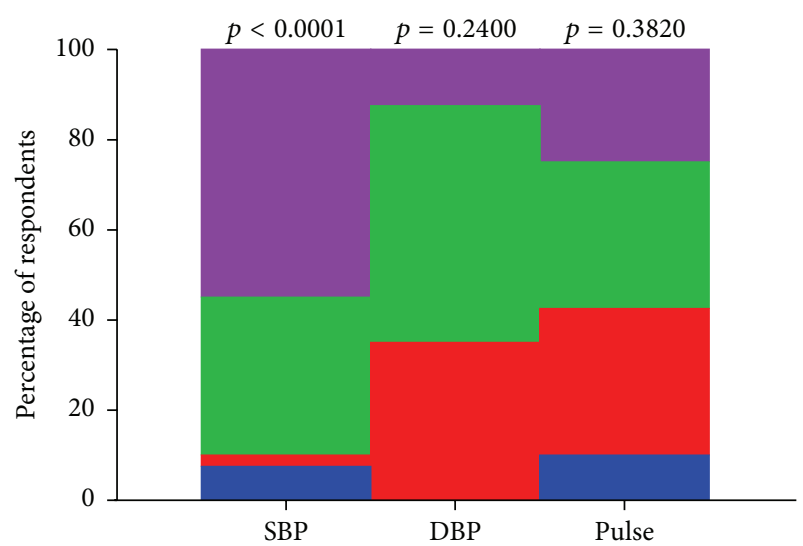

Chronic kidney disease by CG equation
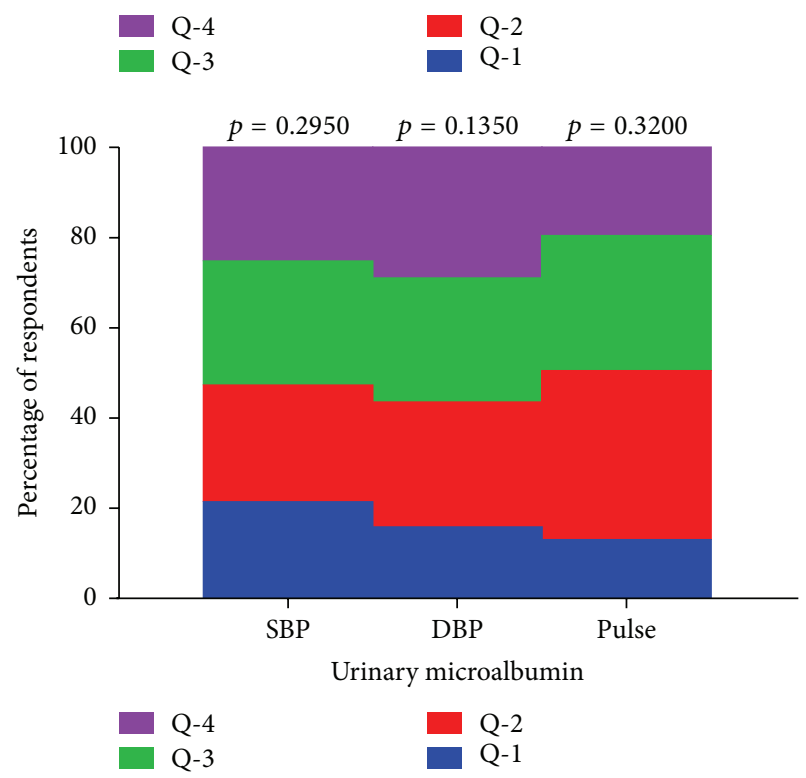

FIGURE 3: Renal insufficiency quartile cluster distributions with haemodynamic parameters. SBP: systolic blood pressure, DBP: diastolic blood pressure, Q-1: first quartile, Q-2: second quartile, Q-3: third quartile, and Q-4: fourth quartile. $p$ value for linear by linear association is significant at 0.05 for two tail.

was perhaps due to differences in study population characteristics; thus, the work of Addo et al. [35] involved a population survey whilst that of Osafo et al. [36] and the present study were hospital-based studies. Again the fact that the study of Osafo et al. [36] included $14.7 \%$ of subjects with preexisting diabetes mellitus whereas the present study involved only nondiabetic hypertensives may account for the higher CKD incidence recorded in the previous report. Adu [37] in an editorial in the Ghana Medical Journal estimated the prevalence of hypertension in the African population at $10 \%$ and posited that hypertension accounts for $38.8 \%$ of the aetiology of CKD and is possibly the leading cause of target kidney organ damage among this population.

The incidence of CKD was higher among the hypertensive study participants on treatment than the treatmentnaïve group. The increased duration of chronic diseases like hypertension has usually been linked with deterioration of sequelae and survival. Also the institution of drug therapy in the management of hypertension is usually associated with advancing disease state and this may account for the higher target kidney organ damage observed among the hypertensives on treatment.

Gender differences in health vary according to differential vulnerabilities in males and females, which may be as a result of biological or sociodemographic differences $[38,39]$. In the case of chronic kidney disease among hypertensives, vulnerability seems to be more tilted toward the female gender than the male gender $[4,40]$. This finding is in agreement with observations made in this study (see Figure 1). Wang et al. [40] have suggested that the stronger association between obesity and chronic kidney disease in women than in men could account for this phenomenon. In Ghana, obesity is reported to be significantly higher among females than in males $[13,41]$. Among hypertensives, obesity was found to be significantly higher $(p=0.0337)$ among females $(57.5 \%)$ compared to the males (40.5\%). 


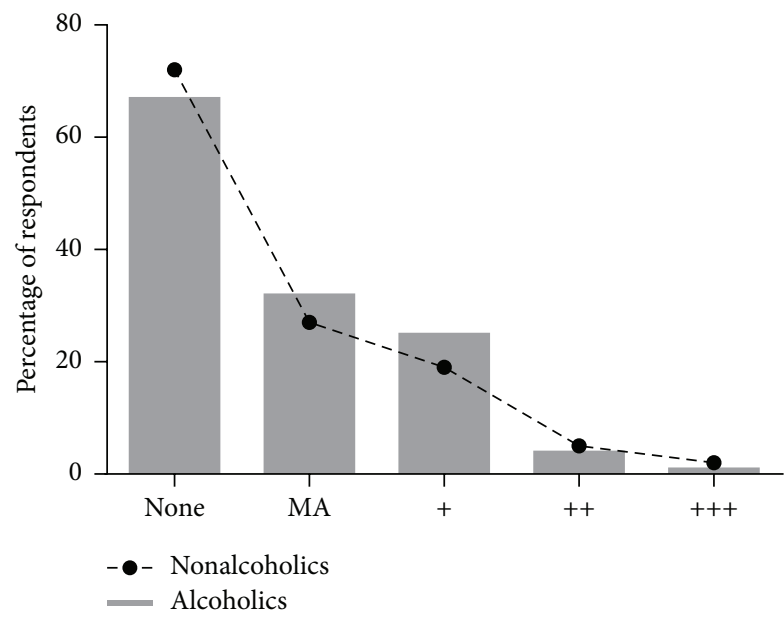

(a)

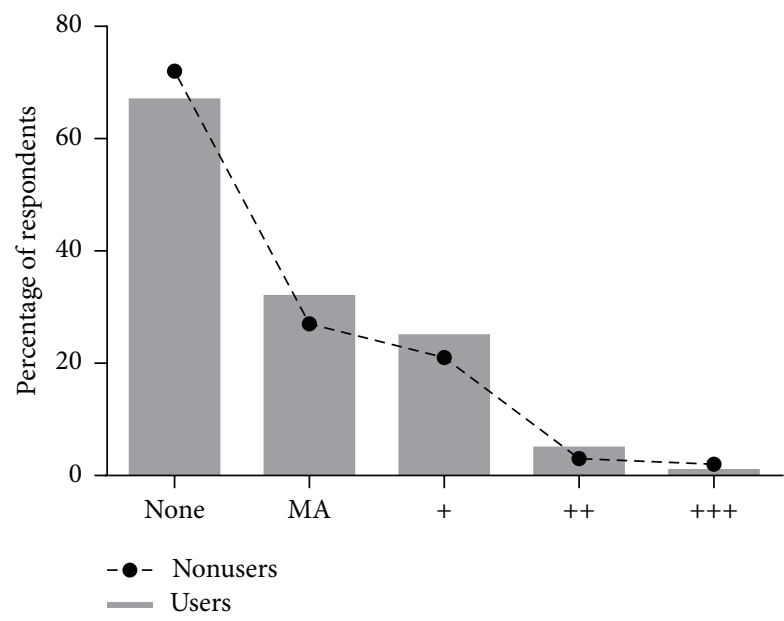

(c)

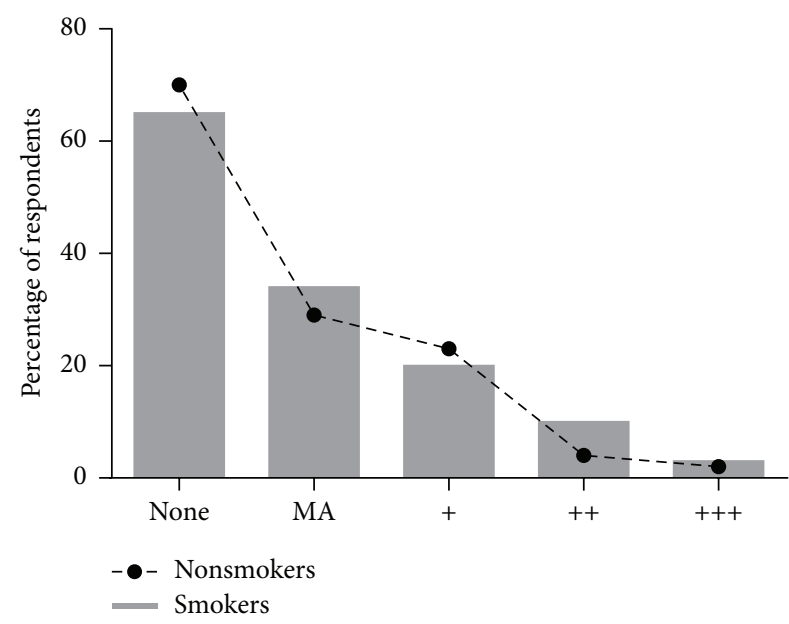

(b)

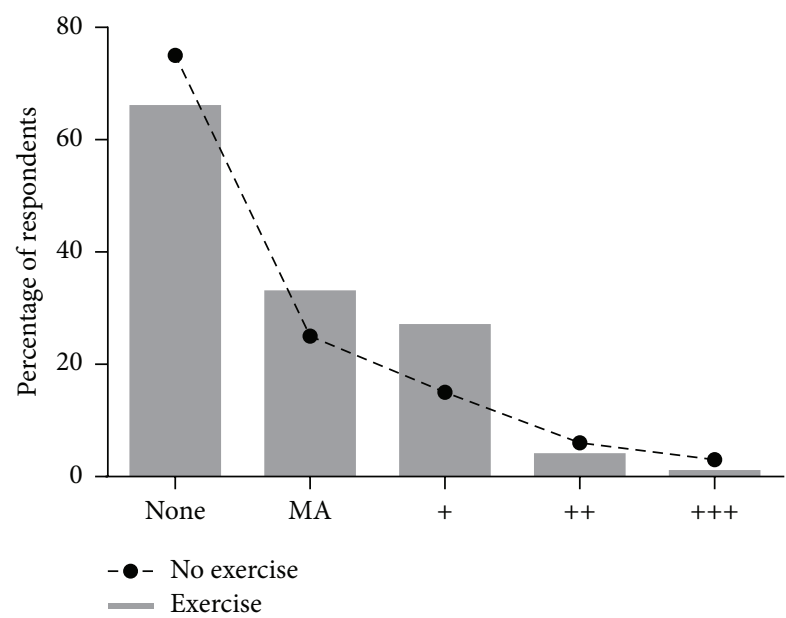

(d)

FIGURE 4: Prevalence of microalbuminuria among hypertension subjects stratified by sociodemographic characteristics. MA: microalbuminuria. (a) Alcohol intake, (b) smoking status, (c) herbal medicine intake, and (d) physical activity level.

The raging debate of alcohol consumption as a modifiable lifestyle trait influencing both hypertension and kidney outcomes in the scientific literature has become even more intense in recent times because of the great importance it confers due to the seemingly large numbers of the population any prognostic outcome may affect. In the current study, selfreported alcohol consumption was recorded among more than half of the study population (130 (53.9\%)) with a significantly higher presence among the hypertensives than the normotensives (see Table 1). Deleterious association of alcohol consumption with hypertension is available in the Ghanaian literature $[10,42,43]$. Plausible mechanisms elucidated for such adverse effects include stimulation of corticosteroid, catecholamine, vasopressin production, and drug interaction causing resistance to drug therapy and direct pressor effect due to alcohol induced arteriolar vasoconstriction [44-46].

The findings of the current study are consistent with those of Renaud et al. [47] and Reynolds et al. [48] both of whom reported an inverse association between alcohol consumption and chronic kidney disease among hypertensives (see Figure 2). However, due to our inability to determine the threshold dose level of alcohol intake among the study population, drawing inferences for causality of alcohol dose response was not possible $[46,49]$. It is therefore appropriate to concur with Reynolds et al. [48] who called for caution in the interpretation of similar results, since epidemiologically a suggested J- or U-shaped relationship exists between alcohol consumption and coronary heart diseases. Thus, the apparent benefits of moderate drinking on kidney and coronary heart disease mortality are offset at higher drinking levels by increasing risk of death from other types of heart diseases (cardiomyopathy, arrhythmia, etc.), neurological disorders, cancer, liver cirrhosis, and traffic accidents $[46,50]$.

Despite the recent report from the HUNT study suggesting smoking is not a major determinant of adverse blood pressure and other component cardiovascular disease risk factors [51] and the report from the population-based Malmö-Diet-and-Cancer-Cohort which found that the associated risk of cardiovascular disease and cardiovascular disease mortality conferred by genetic variation on chromosome 
TABLE 1: Equations for chronic kidney disease epidemiology collaboration (CKD-EPI).

\begin{tabular}{lcc}
\hline Gender & $\begin{array}{c}\text { Serum creatinine } \\
\mu \text { mol } / \mathrm{L}(\mathrm{mg} / \mathrm{dL})\end{array}$ & Estimated glomerular equation \\
\hline Female & $\leq 62(\leq 0.7)$ & $\mathrm{eGFR}=166 \times\left(\frac{\text { Serum Creatinine }}{0.7^{-0.329}}\right) \times(0.993)^{\text {Age }}$ \\
Female & $>62(>0.7)$ & $\mathrm{eGFR}=166 \times\left(\frac{\text { Serum Creatinine }}{0.7^{-1.209}}\right) \times(0.993)^{\mathrm{Age}}$ \\
Male & $\leq 80(\leq 0.9)$ & $\mathrm{eGFR}=163 \times\left(\frac{\text { Serum Creatinine }}{0.9^{-0.411}}\right) \times(0.993)^{\mathrm{Age}}$ \\
Male & $>80(>0.9)$ & $\mathrm{eGFR}=163 \times\left(\frac{\text { Serum Creatinine }}{0.9^{-1.209}}\right) \times(0.993)^{\mathrm{Age}}$ \\
\hline
\end{tabular}

TABLE 2: Sociodemographic characteristics of the population under study stratified by hypertension and treatment status.

\begin{tabular}{lcccc}
\hline Parameter & Control & HPT-naïve & HPT-therapy & $p$ value \\
\hline Respondents & $61(25.3)$ & $40(16.6)$ & $140(58.1)$ & $n d$ \\
Female & $45(73.8)$ & $22(55.0)$ & $84(60.0)$ & 0.0980 \\
Male & $16(26.2)$ & $18(45.0)$ & $56(40.0)$ & \\
Formal sector & $45(74.2)$ & $10(24.4)$ & $44(31.7)$ & $<0.0001$ \\
Informal sector & $16(25.8)$ & $30(75.6)$ & $96(68.3)$ & \\
Alcoholics & $22(36.1)$ & $32(80.0)$ & $76(54.3)$ & $<0.0001$ \\
Smokers & $3(4.9)$ & $9(22.5)$ & $20(14.3)$ & 0.0340 \\
Exercise & $36(59.0)$ & $27(67.5)$ & $89(63.6)$ & 0.6760 \\
Positive family & $40(65.6)$ & $31(77.5)$ & $104(74.3)$ & 0.3330 \\
history & $33(54.1)$ & $24(60.0)$ & $79(56.4)$ & 0.8430 \\
$\begin{array}{l}\text { Herbal medicine } \\
\text { intake }\end{array}$ & $36(59.0)$ & $22(55.0)$ & $82(58.6)$ & 0.9090 \\
$\begin{array}{l}\text { Nonprescribed } \\
\text { drug intake }\end{array}$ & & & & \\
\hline
\end{tabular}

Data is presented as figure with corresponding percentage in parenthesis. HPT-naïve: newly diagnosed hypertensive not on antihypertensive drugs; HPT-therapy: hypertensives on antihypertensives. $p$ is significant at 0.005 .

9 p21 may be attenuated by smoking [52], there is consensus on the association of smoking with adverse cardiovascular and renal outcome [53-59].

In the present study, self-reported smoking was $13.3 \%$ among the total study population and significantly higher among the hypertensives compared to normotensives $(16.1 \%$ versus $4.9 \%)$. In agreement with the findings of adverse renal events associated with cigarette smoking among various study populations [53,60-63], current smoking status was associated with chronic kidney disease among hypertensives (see Figure 2). Plausible mechanisms of smoking attributed renal injury include increased blood pressure and heart rate; altered diurnal blood pressure rhythm; increased sympathetic nerve activity; nicotine induced mesangial cell proliferation and increased production of fibronectin; arteriosclerosis of renal and intrarenal arteries and arterioles; growth factor activation (angiotensin II, endothelin-1, and TGF-1); oxidative stress; impaired lipoprotein and glycosaminoglycan metabolism; tubulotoxicity; direct endothelial cell toxicity; increased aggregation of platelet; modulation of immune mechanisms; vasopressin-mediated antidiuresis and insulin resistance $[4,64]$.

Excess weight gain is a major risk factor for essential hypertension and end-stage renal disease (ESRD) $[65,66]$. In the present study, higher anthropometric indices were recorded among the hypertensive groups compared to the normotensives and, after adjusting for age and gender, positive additive changes in anthropometric indices were associated with corresponding incremental changes in the haemodynamic measurements (hypertension), the serum kidney profile estimates, and renal insufficiency (decreasing eGFR). According to the Guyton hypothesis, sustained hypertension can occur only when there is a derangement of pressure natriuresis $[6,67,68]$. Obesity related resetting of the kidney-fluid apparatus to a hypertensive level is consistent with the model of hypertension by volume overload [69]. Documented pathogenic mechanisms include enhanced sympathetic nervous system activity, increased activity of the systemic renin-angiotensin system, low atrial natriuretic peptide levels, and physical compression of the kidneys by fat deposits within and around the kidneys, coupled with increased abdominal pressure due to accumulation of excess visceral fat, all of which can cause sodium retention $[65,70-72]$. This enhanced sodium avidity shifts the pressure natriuresis curve to the right, thereby necessitating higher arterial pressure to excrete the day's salt intake and maintain sodium balance and volume homeostasis $[67,73]$.

There is an accumulating body of clinical and experimental data implicating obesity as an important causative factor in renal disease [74-76]. Several alterations in renal structure and function have been associated with obesity [77]. The compensatory mechanisms to maintain sodium balance in obesity in the long term lead to increased systemic arterial pressure, creating a haemodynamic burden on the kidneys which causes glomerular injury [65]. Deposition of extracellular matrix throughout the renal medulla and the ducts of Bellini compresses the renal parenchyma toward the pole of the kidney resulting in the formation of roundshaped, enlarged kidneys in obese subjects [69].

There is intense debate as to whether hypertension causes kidney disease or vice versa [4]. High blood pressure is a key pathogenic factor that contributes to the deterioration of kidney function [78]. Conversely, chronic kidney disease (CKD) is the most common form of secondary hypertension 
TABLE 3: Haemodynamic, anthropometric, serum biochemical kidney profile and estimated glomerular filtration rate of the study population stratified by hypertension status.

\begin{tabular}{|c|c|c|c|c|}
\hline Parameter & Control & HPT-naïve & HPT-therapy & $p$ value \\
\hline SBP (mmHg) & $117.38 \pm 0.96$ & $152.00 \pm 3.27$ & $155.46 \pm 1.82$ & $<0.0001$ \\
\hline DBP (mmHg) & $73.28 \pm 0.77$ & $100.50 \pm 1.34$ & $101.46 \pm 0.94$ & $<0.0001$ \\
\hline Pulse (BPM) & $51.41 \pm 0.91$ & $76.85 \pm 2.20$ & $81.74 \pm 1.77$ & $<0.0001$ \\
\hline MAP (mmHg) & $87.98 \pm 0.63$ & $117.67 \pm 1.81$ & $119.46 \pm 1.01$ & $<0.0001$ \\
\hline $\mathrm{WC}(\mathrm{cm})$ & $69.10 \pm 1.57$ & $97.65 \pm 2.80$ & $95.69 \pm 1.58$ & $<0.0001$ \\
\hline $\mathrm{HC}(\mathrm{cm})$ & $71.82 \pm 1.56$ & $102.20 \pm 3.20$ & $101.42 \pm 2.12$ & $<0.0001$ \\
\hline $\operatorname{BMI}\left(\mathrm{Kg} / \mathrm{m}^{2}\right)$ & $29.36 \pm 0.65$ & $29.80 \pm 0.71^{\mathrm{a}}$ & $29.52 \pm 0.39^{\mathrm{a}}$ & 0.9018 \\
\hline WHR & $0.96 \pm 0.01$ & $0.97 \pm 0.01^{\mathrm{a}}$ & $0.97 \pm 0.0^{\mathrm{a}}$ & 0.9356 \\
\hline WHtR & $0.45 \pm 0.01$ & $0.60 \pm 0.11$ & $0.59 \pm 0.13$ & $<0.0001$ \\
\hline AVI & $9.86 \pm 0.45$ & $19.74 \pm 1.16$ & $19.09 \pm 0.66$ & $<0.0001$ \\
\hline Conicity index & $0.929 \pm 0.11$ & $1.28 \pm 0.04$ & $1.25 \pm 0.02$ & $<0.0001$ \\
\hline BAI & $19.49 \pm 0.90$ & $31.14 \pm 1.60$ & $31.40 \pm 1.17$ & $<0.0001$ \\
\hline Potassium (mmol/L) & $3.20 \pm 1.03$ & $3.76 \pm 1.05$ & $3.82 \pm 1.03$ & 0.0001 \\
\hline Sodium (mmol/L) & $134.89 \pm 1.35$ & $139.43 \pm 3.20$ & $146.86 \pm 2.39$ & $<0.0001$ \\
\hline Chloride (mmol/L) & $94.89 \pm 1.35$ & $106.13 \pm 1.12$ & $112.73 \pm 1.03$ & $<0.0001$ \\
\hline Urea (mmol/L) & $3.71 \pm 0.09$ & $5.66 \pm 0.31$ & $5.77 \pm 0.14$ & $<0.0001$ \\
\hline Creatinine $(\mu \mathrm{mol} / \mathrm{L})$ & $69.08 \pm 1.48$ & $86.81 \pm 4.29$ & $91.71 \pm 2.38$ & $<0.0001$ \\
\hline Uric acid $(\mu \mathrm{mol} / \mathrm{L})$ & $125.68 \pm 1.02$ & $157.19 \pm 1.07$ & $176.66 \pm 1.05$ & $<0.0001$ \\
\hline Microalbuminuria (mg) & $4.52 \pm 1.14$ & $5.60 \pm 1.21^{\mathrm{a}}$ & $7.38 \pm 1.12$ & 0.0336 \\
\hline $4 \mathrm{v}-\mathrm{MDRD}\left(\mathrm{mL} / \mathrm{min} / 1.73 \mathrm{~m}^{2}\right)$ & $127.63 \pm 1.03$ & $101.78 \pm 1.13^{\mathrm{a}}$ & $87.05 \pm 1.06$ & 0.0002 \\
\hline $\mathrm{CG}\left(\mathrm{mL} / \mathrm{min} / 1.73 \mathrm{~m}^{2}\right)$ & $130.24 \pm 1.03$ & $103.26 \pm 1.12^{\mathrm{a}}$ & $82.61 \pm 1.05$ & $<0.0001$ \\
\hline CKD-EPI $\left(\mathrm{mL} / \mathrm{min} / 1.73 \mathrm{~m}^{2}\right)$ & $131.23 \pm 1.03$ & $90.33 \pm 1.06$ & $81.49 \pm 1.05$ & $<0.0001$ \\
\hline
\end{tabular}

Data is presented as mean \pm standard error of the mean. HPT-naive: newly diagnosed hypertensive not on antihypertensive drugs, HPT-therapy: hypertensives on antihypertensives, SBP: systolic blood pressure, DBP: diastolic blood pressure, MAP: mean arterial pressure, WC: waist circumference, HC: hip circumference, BMI: body mass index, WHR: waist-to-hip ratio, WHtR: waist-to-height ratio, AVI: abdominal volume index, BAI: body adiposity index, 4vMDRD: four-variable modification of diet in renal disease, CG: Cockcroft-Gault, CKD-EPI: chronic kidney disease epidemiology collaboration. Bonferroni post hoc ${ }^{\mathrm{a}}$ : no statistically significant difference compared with control.

[6], thus making the kidney both a cause and a victim of hypertension [5]. In the current study, chronic kidney disease was observed only among the participants presenting with hypertension, irrespective of the predictive equation used in estimating the glomerular filtration rate. The association between hypertension and CKD was also evident as percentage cluster distribution of participants presenting with chronic kidney disease predominantly segregated with the upper quartiles (3rd and 4th quartiles) of the haemodynamic indices (SBP, DBP, and pulse; see Figure 3). The strength of association was found to be more pronounced with systolic blood pressure rather than diastolic blood pressure, posing a greater risk for cardiovascular events and kidney disease progression.

Serum elevation of kidney excretory products like electrolytes and metabolites of purine and amino acid catabolism (uric acid and urea) in hypertensives has traditionally been attributed to decreased glomerular filtration rate (GFR) as a result of the effect of hypertension on renal function. A reduction in renal blood flow as a consequence of increasing renal vascular resistance leads to decreased distal tubular flow rate which leads to increased reabsorption and decreased excretion $[68,79,80]$. Significantly higher levels of serum electrolytes as well as urea and uric acid were observed among the hypertensive subgroup compared to their normotensive counterparts (see Table 2). The assertion that serum kidney excretory products are only secondary to residual confounding factors that have a pathogenically inert relationship with hypertension and renal disease is giving way. Serum kidney excretory products are now viewed as pathophysiologically active independent attribution factors for the cause and progression of hypertension and renal disease [81-85].

Linear additive relationship was observed for all serum electrolytes as well as urea and uric acid with progressive quartile increment of haemodynamic indices measured in this study. After adjusting for age and gender in the present study, surfeit urea and uric acid were significantly associated with renal insufficiency (see Table 3). Often considered a beneficial antioxidant, recent epidemiologic and experimental studies have demonstrated that hyperuricaemia is a major and an independent risk factor for the development of renal disease, hypertension, and adverse cardiovascular outcome $[79,83,84,86,87]$. Possible adverse effects of uric acid on the vasculature have been linked to increased chemokine and cytokine expression [88], induction of renal vasoconstriction mediated by endothelial dysfunction, activation of the reninangiotensin system [87], and stimulation of oxidative stress in vascular smooth muscle cell (VSMC) proliferation, mediated 


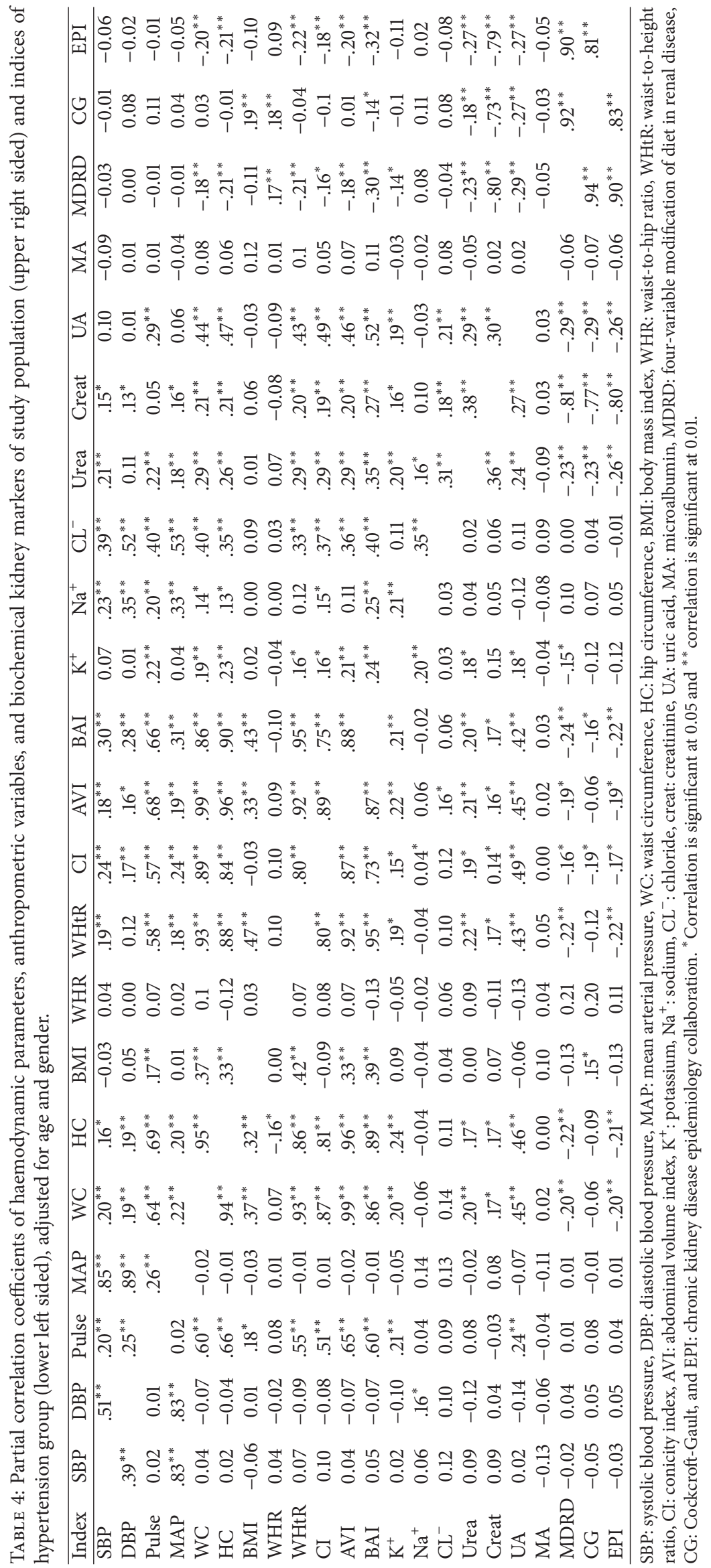


TABLE 5: Estimates of the prevalence of CKD in the study population using the renal function equations.

\begin{tabular}{|c|c|c|c|c|c|c|c|c|c|}
\hline Parameter & & 4v-MDRD & & & CG & & & CKD-EPI & \\
\hline $\mathrm{eGFR}\left(\mathrm{mL} / \mathrm{min} / 1.73 \mathrm{~m}^{2}\right)$ & Total & Control & Case & Total & Control & Case & Total & Control & Case \\
\hline Stage $1(\geq 90)$ & $120(49.80)$ & $57(93.40)$ & $63(35.00)$ & $136(56.40)$ & $57(93.40)$ & $79(43.90)$ & $117(48.50)$ & $59(96.70)$ & $58(32.20)$ \\
\hline Stage 2 (60 to 89 ) & $89(36.90)$ & $4(6.60)$ & $85(47.20)$ & $65(27.00)$ & $4(6.60)$ & $61(33.90)$ & $89(36.90)$ & $2(3.30)$ & $87(48.30)$ \\
\hline Stage 3 (30 to 59 ) & $32(13.30)$ & $0(0.00)$ & $32(17.80)$ & $39(16.20)$ & $0(0.00)$ & $39(21.70)$ & $35(14.50)$ & $0(0.00)$ & $35(14.50)$ \\
\hline Stage 4 (15 to 29$)$ & $0(0.00)$ & $0(0.00)$ & $0(0.00)$ & $1(0.40)$ & $0(0.00)$ & $1(0.60)$ & $0(0.00)$ & $0(0.00)$ & $0(0.00)$ \\
\hline Stage $5(<15)$ & $0(0.00)$ & $0(0.00)$ & $0(0.00)$ & $0(0.00)$ & $0(0.00)$ & $0(0.00)$ & $0(0.00)$ & $0(0.00)$ & $0(0.00)$ \\
\hline CKD (Stages $3+4+5)$ & $32(13.30)$ & $0(0.00)$ & $32(17.80)$ & $40(16.60)$ & $0(0.00)$ & $40(22.22)$ & $35(14.50)$ & $0(0.00)$ & $35(19.40)$ \\
\hline
\end{tabular}

Data is presented as absolute values with corresponding percentage in parenthesis. 4v-MDRD: four variable modification of diet in renal disease, CG: CockcroftGault, CKD-EPI: chronic kidney disease epidemiology collaboration, eGFR: estimated glomerular filtration rate, and CKD: chronic kidney disease.

TABLE 6: Staged renal insufficiency stratified by the presence of clinical manifestation of cardiac disorder (nonspecific sinuses, left ventricular hypertrophy, and heart enlargement).

\begin{tabular}{|c|c|c|c|c|c|c|c|}
\hline Parameter & Equation & Condition & Stage 1 & Stage 2 & Stage 3 & Stage 4 & $p$ value \\
\hline \multirow{6}{*}{$\begin{array}{l}\text { Left ventricular hypertrophy } \\
\text { (electrocardiograph) }\end{array}$} & \multirow{2}{*}{ 4v-MDRD } & Absent & $66(74.12)$ & $17(19.10)$ & $6(6.74)$ & $0(0.00)$ & \multirow{2}{*}{$p<0.0001$} \\
\hline & & Present & $54(35.53)$ & $72(47.37)$ & $26(17.11)$ & $0(0.00)$ & \\
\hline & \multirow{2}{*}{ CG } & Absent & $68(76.40)$ & $12(13.48)$ & $9(10.11)$ & $0(0.00)$ & \multirow{2}{*}{$p<0.0001$} \\
\hline & & Present & $68(44.74)$ & $53(34.87)$ & $30(19.74)$ & $1(0.67)$ & \\
\hline & \multirow{2}{*}{ CKD-EPI } & Absent & $66(74.16)$ & $17(19.10)$ & $6(6.74)$ & $0(0.00)$ & \multirow{2}{*}{$p<0.0001$} \\
\hline & & Present & $51(33.55)$ & $72(47.37)$ & $29(19.08)$ & $0(0.00)$ & \\
\hline \multirow{6}{*}{$\begin{array}{l}\text { Left ventricular hypertrophy } \\
\text { (echocardiograph) }\end{array}$} & \multirow{2}{*}{$4 \mathrm{v}-\mathrm{MDRD}$} & Absent & $62(76.54)$ & $16(19.75)$ & $3(3.70)$ & $0(0.00)$ & \multirow{2}{*}{$p<0.0001$} \\
\hline & & Present & $58(36.25)$ & $73(45.63)$ & $29(18.13)$ & $0(0.00)$ & \\
\hline & \multirow{2}{*}{ CG } & Absent & $65(80.25)$ & $12(14.83)$ & $4(4.94)$ & $0(0.00)$ & \multirow{2}{*}{$p<0.0001$} \\
\hline & & Present & $71(44.38)$ & $53(33.13)$ & $35(21.88)$ & $1(0.63)$ & \\
\hline & \multirow{2}{*}{ CKD-EPI } & Absent & $64(79.00)$ & $14(17.30)$ & $3(3.70)$ & $0(0.00)$ & \multirow{2}{*}{$p<0.0001$} \\
\hline & & Present & $53(33.10)$ & $75(46.90)$ & $32(20.00)$ & $0(0.00)$ & \\
\hline \multirow{6}{*}{ Cardiomegaly (X-ray) } & \multirow{2}{*}{$4 \mathrm{v}-\mathrm{MDRD}$} & Absent & $74(71.80)$ & $21(20.40)$ & $8(7.80)$ & $0(0.00)$ & \multirow{2}{*}{$p<0.0001$} \\
\hline & & Present & $46(33.30)$ & $68(49.30)$ & $24(17.40)$ & $0(0.00)$ & \\
\hline & \multirow{2}{*}{ CG } & Absent & $79(76.70)$ & 18 (17.48) & $6(5.83)$ & $0(0.00)$ & \multirow{2}{*}{$p<0.0001$} \\
\hline & & Present & $57(41.30)$ & $47(34.06)$ & $33(23.91)$ & $1(0.73)$ & \\
\hline & \multirow{2}{*}{ CKD-EPI } & Absent & $64(79.00)$ & $14(17.30)$ & $3(3.70)$ & $0(0.00)$ & \multirow{2}{*}{$p<0.0001$} \\
\hline & & Present & $53(33.10)$ & $75(46.90)$ & $32(20.00)$ & $0(0.00)$ & \\
\hline
\end{tabular}

Data is presented as figure with percentage in parenthesis. 4v-MDRD: four-variable modification of diet in renal disease, CG: Cockcroft-Gault, and CKD-EPI: chronic kidney disease epidemiology collaboration equation.

by the mitogen-activated protein (MAP) kinase pathway [89] and increased vascular C-reactive protein (CRP) expression [88].

\section{Conclusion}

In this urban population, chronic kidney disease was associated with hypertension and cardiac abnormalities. Adiposity was associated with hypertension and renal insufficiency. Modifiable lifestyle practices (smoking and alcoholism) increased the risk of hypertension, whilst smoking increased kidney target organ damage among hypertensives.

\section{Additional Points}

Limitation of Study. The threshold dose level of alcohol intake could not be established from this study; thus, inferences for causality of alcohol dose response were not feasible. Further studies will be required to help determine the threshold dose of alcohol intake.

\section{Ethical Approval}

The participation of the respondents who are all indigenes of Ghana was voluntary and informed consent was obtained from each of them after thorough explanation of what the study entailed. This study was approved by the School of Medical Sciences and KATH Committee on Human Research Publications and Ethics (CHRPE/08/11).

\section{Competing Interests}

The authors have declared that no competing interests exist. 


\section{Authors' Contributions}

This work was carried out in collaboration between all authors. Authors William K. B. A. Owiredu, Isaac K. Owusu, Edwin F. Laing, Ellis Owusu-Dabo, and James Osei-Yeboah conceptualized and designed the study. Authors Isaac K. Owusu, Christiana Aryee, and Ellis Owusu-Dabo recruited the study participants. Authors Isaac K. Owusu, Christiana Aryee, James Osei-Yeboah, William K. B. A. Owiredu, and Ellis Owusu-Dabo generated the data. Authors Christiana Aryee, James Osei-Yeboah, William K. B. A. Owiredu, and Isaac K. Owusu analyzed the data. Authors Isaac K. Owusu, Christiana Aryee, William K. B. A. Owiredu, and James OseiYeboah drafted the manuscript. Authors Isaac K. Owusu, Christiana Aryee, William K. B. A. Owiredu, James OseiYeboah, Ellis Owusu-Dabo, and Edwin F. Laing reviewed the manuscript for intellectual content and each author approved the final manuscript.

\section{Acknowledgments}

The authors' gratitude goes to the doctors, nurses, and ancillary staff of the cardiac clinic of Komfo Anokye Teaching Hospital for their assistance during the study period. The authors are also most grateful to the nurses of the Precise Specialist Clinic for their dedicated service during the segment of the study at their clinic. The authors are most indebted to the Biomedical Scientists at the Kumasi Centre for Collaborative Research in Tropical Medicine especially Mr. Michael Frimpong and Miss Esimebia Agbodidi for their assistance in the assays. The authors are thankful for the insightful suggestions of Dr. Christian Obirikorang, Department of Molecular Medicine.

\section{References}

[1] D. B. Munaretti, A. R. Barbosa, M. D. F. N. Marucci, and M. L. Lebrão, "Self-rated hypertension and anthropometric indicators of body fat in elderly," Revista da Associacao Medica Brasileira, vol. 57, no. 1, pp. 25-30, 2011.

[2] G. Ogedegbe, J. Plange-Rhule, J. Gyamfi et al., "A clusterrandomized trial of task shifting and blood pressure control in Ghana: study protocol," Implementation Science, vol. 9, no. 1, article 73, 2014.

[3] P. Stenvinkel, J. J. Carrero, J. Axelsson, B. Lindholm, O. Heimbürger, and Z. Massy, "Emerging biomarkers for evaluating cardiovascular risk in the chronic kidney disease patient: how do new pieces fit into the uremic puzzle?" Clinical Journal of the American Society of Nephrology, vol. 3, no. 2, pp. 505-521, 2008.

[4] M. K. Haroun, B. G. Jaar, S. C. Hoffman, G. W. Comstock, M. J. Klag, and J. Coresh, "Risk factors for chronic kidney disease: a prospective study of 23,534 men and women in Washington County, Maryland," Journal of the American Society of Nephrology, vol. 14, no. 11, pp. 2934-2941, 2003.

[5] E. Morgado and P. L. Neves, "Hypertension and chronic kidney disease: cause and consequence-therapeutic considerations," in Antihypertensive Drugs, 2012.

[6] F. M. Tedla, A. Brar, R. Browne, and C. Brown, "Hypertension in chronic kidney disease: navigating the evidence," International
Journal of Hypertension, vol. 2011, Article ID 132405, 9 pages, 2011.

[7] Y. Commodore-Mensah, L. J. Samuel, C. R. DennisonHimmelfarb, and C. Agyemang, "Hypertension and overweight/obesity in Ghanaians and Nigerians living in West Africa and industrialized countries: a systematic review," Journal of Hypertension, vol. 32, no. 3, pp. 464-472, 2014.

[8] W. Owiredu, R. Ephraim, N. Amidu, B. E. Jnr, and E. Laing, "Oxidative stress among ghanaian patients presenting with chronic kidney disease," Journal of Medical and Biomedical Sciences, vol. 1, no. 1, pp. 28-37, 2012.

[9] K. Entsua-Mensah, A. Doku, and I. Adzamli, "The National cardiothoracic centre, Accra Ghana: proceedings of the second International update course in cardiology-improving the coverage of cardiology services," Pan African Medical Journal, vol. 11, no. 1, 2012.

[10] J. Addo, C. Agyemang, L. Smeeth, A. D. G. Aikins, A. K. Edusei, and O. Ogedegbe, "A review of population-based studies on hypertension in Ghana," Ghana Medical Journal, vol. 46, no. 2, pp. 4-11, 2012.

[11] S. Agyei-Mensah and A. de-Graft Aikins, "Epidemiological transition and the double burden of disease in Accra, Ghana," Journal of Urban Health, vol. 87, no. 5, pp. 879-897, 2010.

[12] G. Santulli, M. Ciccarelli, B. Trimarco, and G. Iaccarino, "Physical activity ameliorates cardiovascular health in elderly subjects: the functional role of the $\beta$ adrenergic system," Frontiers in Physiology, vol. 4, article 209, 2013.

[13] R. Biritwum, J. Gyapong, and G. Mensah, "The epidemiology of obesity in Ghana," Ghana Medical Journal, vol. 39, no. 3, p. 82, 2005.

[14] E.-M. Backé, A. Seidler, U. Latza, K. Rossnagel, and B. Schumann, "The role of psychosocial stress at work for the development of cardiovascular diseases-a systematic review," International Archives of Occupational and Environmental Health, vol. 85, no. 1, pp. 67-79, 2012.

[15] R. Gillum, M. Mussolino, and J. Madans, "Body fat distribution and hypertension incidence in women and men. The NHANES I epidemiologic follow-up study," International Journal of Obesity and Related Metabolic Disorders, vol. 22, no. 2, pp. 127-134, 1998.

[16] D. Blair, J.-P. Habicht, E. A. Sims, D. Sylwester, and S. Abraham, "Evidence for an increased risk for hypertension with centrally located body fat and the effect of race and sex on this risk," American Journal of Epidemiology, vol. 119, no. 4, pp. 526-540, 1984.

[17] P. Parab-Waingankar and S. Rao, "Obesity and hypertension among urban affluent adult males from Pune, India," The Indian Journal of Nutrition and Dietetics, vol. 52, no. 1, pp. 32-44, 2015.

[18] A. Chandra and A. T. Turer, "Reply: does body adiposity better predict obesity-associated cardiometabolic risk than body mass index?" Journal of the American College of Cardiology, vol. 65, no. 6, pp. 633-633, 2015.

[19] S. Anoop, A. Misra, S. Bhardwaj, and S. Gulati, "High body fat and low muscle mass are associated with increased arterial stiffness in Asian Indians in North India," Journal of Diabetes and Its Complications, vol. 29, no. 1, pp. 38-43, 2015.

[20] S. Wang, Y. Liu, F. Li, H. Jia, L. Liu, and F. Xue, "A novel quantitative body shape score for detecting association between obesity and hypertension in China," BMC Public Health, vol. 15, no. 1, article 7, 2015.

[21] Y.-X. Zhang and S.-R. Wang, "Distribution of subcutaneous fat and the relationship with blood pressure in obese children 
and adolescents in Shandong, China," Paediatric and Perinatal Epidemiology, vol. 29, no. 2, pp. 156-161, 2015.

[22] N. C. Sundgren, W. Vongpatanasin, B.-M. D. Boggan et al., "IgG receptor Fc $\gamma$ RIIB plays a key role in obesity-induced hypertension," Hypertension, vol. 65, no. 2, pp. 456-462, 2015.

[23] J. Axelsson, "The emerging biology of adipose tissue in chronic kidney disease: from fat to facts," Nephrology Dialysis Transplantation, vol. 23, no. 10, pp. 3041-3046, 2008.

[24] P. Iglesias and J. J. Díez, "Adipose tissue in renal disease: clinical significance and prognostic implications," Nephrology Dialysis Transplantation, vol. 25, no. 7, pp. 2066-2077, 2010.

[25] R. Agarwal, J. E. Bills, and R. P. Light, "Diagnosing obesity by body mass index in chronic kidney disease: an explanation for the 'obesity paradox?'” Hypertension, vol. 56, no. 5, pp. 893-900, 2010.

[26] I. K. Owusu, C. Aryee, W. K. Owiredu, J. Osei-Yeboah, E. Owusu-Dabo, and E. Laing, "Analysis of atherogenic and anthropometric profiles of normotensive and hypertensive ghanaians in the kumasi metropolis," British Journal of Medicine and Medical Research, vol. 7, no. 5, pp. 378-397, 2015.

[27] D. Lemogoum, Y. K. Seedat, A. F. B. Mabadeje et al., "Recommendations for prevention, diagnosis and management of hypertension and cardiovascular risk factors in sub-Saharan Africa," Journal of Hypertension, vol. 21, no. 11, pp. 1993-2000, 2003.

[28] I. K. Owusu, "Causes of heart failure as seen in Kumasi Ghana," Internet Journal of Third World Medicine, vol. 4, no. 3, 2007.

[29] M. Ruperto, G. Barril, and F. J. Sánchez-Muniz, "Conicity index as a contributor marker of inflammation in haemodialysis patients," Nutricion Hospitalaria, vol. 28, no. 5, pp. 1688-1695, 2013.

[30] M. Vuga, "Conceptual review of issues with practical abdominal obesity measures," in Section on Statistics in Epidemiology-JSM, 2009.

[31] R. Lategan, V. L. Van den Berg, and C. M. Walsh, "Body adiposity indices are associated with hypertension in a black, urban Free State community: original research," African Primary Health Care and Family Medicine, vol. 6, no. 1, pp. 1-7, 2014.

[32] KDOQI, "Clinical practice guidelines and clinical practice recommendations for anemia in chronic kidney disease," American Journal of Kidney Diseases, vol. 47, pp. S11-S145, 2006.

[33] A. S. Levey, K.-U. Eckardt, Y. Tsukamoto et al., "Definition and classification of chronic kidney disease: a position statement from Kidney Disease: Improving Global Outcomes (KDIGO)," Kidney International, vol. 67, no. 6, pp. 2089-2100, 2005.

[34] P. A. McKee, W. P. Castelli, P. M. McNamara, and W. B. Kannel, "The natural history of congestive heart failure: the Framingham study," The New England Journal of Medicine, vol. 285, no. 26, pp. 1441-1446, 1971.

[35] J. Addo, L. Smeeth, and D. A. Leon, "Hypertensive target organ damage in Ghanaian civil servants with hypertension," PLoS ONE, vol. 4, no. 8, Article ID e6672, 2009.

[36] C. Osafo, M. Mate-Kole, K. Affram, and D. Adu, "Prevalence of chronic kidney disease in hypertensive patients in ghana," Renal Failure, vol. 33, no. 4, pp. 388-392, 2011.

[37] D. Adu, "Haemodialysis treatment for end stage chronic kidney disease and acute kidney injury in Africa," Ghana Medical Journal, vol. 47, no. 1, pp. 1-2, 2013.

[38] H.-Y. Shin, M.-H. Shin, and J.-A. Rhee, "Gender differences in the association between self-rated health and hypertension in a Korean adult population," BMC Public Health, vol. 12, article 135, 2012.
[39] A. A. Saeed, N. A. Al-Hamdan, A. A. Bahnassy, A. M. Abdalla, M. A. F. Abbas, and L. Z. Abuzaid, "Prevalence, awareness, treatment, and control of hypertension among Saudi adult population: a national survey," International Journal of Hypertension, vol. 2011, Article ID 174135, 8 pages, 2011.

[40] Y. Wang, X. Chen, Y. Song, B. Caballero, and L. J. Cheskin, "Association between obesity and kidney disease: a systematic review and meta-analysis," Kidney International, vol. 73, no. 1, pp. 19-33, 2008.

[41] A. G. B. Amoah, "Sociodemographic variations in obesity among Ghanaian adults," Public Health Nutrition, vol. 6, no. 8, pp. 751-757, 2003.

[42] W. K. Bosu, "Epidemic of hypertension in Ghana: a systematic review," BMC Public Health, vol. 10, no. 1, article 418, 2010.

[43] A. A. Newlove, W. B. Owusu, and A. Charles, "The relationship between lifestyle variables, blood pressure and dietary habits of male adult miners in Ghana," Asian Journal of Clinical Nutrition, vol. 4, no. 3, pp. 98-106, 2012.

[44] L. J. Beilin and I. B. Puddey, "Alcohol and hypertension," Clinical and Experimental Hypertension-Part A: Theory and Practice, vol. 14, no. 1-2, pp. 119-138, 1992.

[45] J. F. Potter, L. T. Bannan, and D. G. Beevers, "Alcohol and hypertension," British Journal of Addiction, vol. 79, no. 4, pp. 365-372, 1984.

[46] A. L. Klatsky, "Alcohol-associated hypertension: when one drinks makes a difference," Hypertension, vol. 44, no. 6, pp. 805806, 2004

[47] S. C. Renaud, R. Guéguen, P. Conard, D. Lanzmann-Petithory, J.-M. Orgogozo, and O. Henry, "Moderate wine drinkers have lower hypertension-related mortality: a prospective cohort study in French men," American Journal of Clinical Nutrition, vol. 80, no. 3, pp. 621-625, 2004.

[48] K. Reynolds, D. Gu, J. Chen et al., "Alcohol consumption and the risk of end-stage renal disease among Chinese men," Kidney International, vol. 73, no. 7, pp. 870-876, 2008.

[49] M. C. Dufour, "What is moderate drinking," Alcohol Research \& Health, vol. 23, no. 1, pp. 5-14, 1999.

[50] D. P. Agarwal, "Cardioprotective effects of light-moderate consumption of alcohol: a review of putative mechanisms," Alcohol and Alcoholism, vol. 37, no. 5, pp. 409-415, 2002.

[51] B. O. Åsvold, J. H. Bjørngaard, D. Carslake et al., "Causal associations of tobacco smoking with cardiovascular risk factors: a Mendelian randomization analysis of the HUNT study in Norway," International Journal of Epidemiology, vol. 43, no. 5, pp. 1458-1470, 2014.

[52] V. Hamrefors, B. Hedblad, G. Hindy et al., "Smoking modifies the associated increased risk of future cardiovascular disease by genetic variation on chromosome 9p21," PLOS ONE, vol. 9, no. 1, Article ID e85893, 2014.

[53] N. Ishizaka, Y. Ishizaka, E.-I. Toda et al., "Association between cigarette smoking and chronic kidney disease in Japanese men," Hypertension Research, vol. 31, no. 3, pp. 485-492, 2008.

[54] S. R. Orth, H. Ogata, and E. Ritz, "Smoking and the kidney," Nephrology Dialysis Transplantation, vol. 15, no. 10, pp. 15091511, 2000.

[55] W. C. Willett, A. Green, M. J. Stampfer et al., "Relative and absolute excess risks of coronary heart disease among women who smoke cigarettes," The New England Journal of Medicine, vol. 317, no. 21, pp. 1303-1309, 1987.

[56] F. Doyle, D. Rohde, A. Rutkowska, K. Morgan, G. Cousins, and H. McGee, "Systematic review and meta-analysis of the impact 
of depression on subsequent smoking cessation in patients with coronary heart disease: 1990 to 2013," Psychosomatic Medicine, vol. 76, no. 1, pp. 44-57, 2014.

[57] A. S. Go, D. Mozaffarian, V. L. Roger et al., "Heart disease and stroke statistics 2014 update: a report from the American Heart Association," Circulation, vol. 129, no. 3, pp. e28-e292, 2014.

[58] R. M. Nance, J. A. Delaney, M. Blaha et al., "Abstract P133: modeling smoking in relation to cardiovascular disease risk in the multi-ethnic study of atherosclerosis (MESA)," Circulation, vol. 129, supplement 1, Article ID AP133, 2014.

[59] J. S. Tolstrup, U. A. Hvidtfeldt, E. M. Flachs et al., "Smoking and risk of coronary heart disease in younger, middle-aged, and older adults," American Journal of Public Health, vol. 104, no. 1, pp. 96-102, 2014.

[60] I. Maeda, T. Hayashi, K. K. Sato et al., "Cigarette smoking and the association with glomerular hyperfiltration and proteinuria in healthy middle-aged men," Clinical Journal of the American Society of Nephrology, vol. 6, no. 10, pp. 2462-2469, 2011.

[61] L. Ryom, A. Mocroft, O. Kirk et al., "Predictors of advanced chronic kidney disease and end-stage renal disease in HIVpositive persons," AIDS, vol. 28, no. 2, pp. 187-199, 2014.

[62] K. Yamagata, K. Ishida, T. Sairenchi et al., "Risk factors for chronic kidney disease in a community-based population: a 10year follow-up study," Kidney International, vol. 71, no. 2, pp. 159-166, 2007.

[63] B. Stengel, M. E. Tarver-Carr, N. R. Powe, M. S. Eberhardt, and F. L. Brancati, "Lifestyle factors, obesity and the risk of chronic kidney disease," Epidemiology, vol. 14, no. 4, pp. 479-487, 2003.

[64] S. R. Orth and S. I. Hallan, "Smoking: a risk factor for progression of chronic kidney disease and for cardiovascular morbidity and mortality in renal patients-absence of evidence or evidence of absence?" Clinical Journal of the American Society of Nephrology, vol. 3, no. 1, pp. 226-236, 2008.

[65] J. E. Hall, J. R. Henegar, T. M. Dwyer et al., "Is obesity a major cause of chronic kidney disease?" Advances in Renal Replacement Therapy, vol. 11, no. 1, pp. 41-54, 2004.

[66] P. Mathieu, P. Poirier, P. Pibarot, I. Lemieux, and J.-P. Després, "Visceral obesity the link among inflammation, hypertension, and cardiovascular disease," Hypertension, vol. 53, no. 4, pp. 577-584, 2009.

[67] R. N. Re, "Obesity-related hypertension," Journal Information, vol. 9, no. 3, 2009.

[68] I. A. H. AL-Hamdani, "Estimation of serum uric acid, urea and creatinine in essential hypertensive patients," Tikrit Medical Journal, vol. 16, no. 1, 2010.

[69] V. Kotsis, S. Stabouli, S. Papakatsika, Z. Rizos, and G. Parati, "Mechanisms of obesity-induced hypertension," Hypertension Research, vol. 33, no. 5, pp. 386-393, 2010.

[70] A. H. A. Mazairac and J. A. Joles, "Renal sinus adiposity and hypertension," Hypertension, vol. 56, no. 5, pp. 814-815, 2010.

[71] A. M. Sharma, S. Engeli, and T. Pischon, "New developments in mechanisms of obesity-induced hypertension: role of adipose tissue," Current Hypertension Reports, vol. 3, no. 2, pp. 152-156, 2001.

[72] J. E. Hall, A. A. da Silva, J. M. do Carmo et al., "Obesity-induced hypertension: role of sympathetic nervous system, leptin, and melanocortins," The Journal of Biological Chemistry, vol. 285, no. 23, pp. 17271-17276, 2010.

[73] L. Landsberg, L. J. Aronne, L. J. Beilin et al., "Obesityrelated hypertension: pathogenesis, cardiovascular risk, and treatment," The Journal of Clinical Hypertension, vol. 15, no. 1, pp. 14-33, 2013.
[74] S. D. Navaneethan, J. P. Kirwan, S. Arrigain, M. J. Schreiber, M. J. Sarnak, and J. D. Schold, "Obesity, anthropometric measures and chronic kidney disease complications," American Journal of Nephrology, vol. 36, no. 3, pp. 219-227, 2012.

[75] E. Ejerblad, C. M. Fored, P. Lindblad, J. Fryzek, J. K. McLaughlin, and O. Nyrén, "Obesity and risk for chronic renal failure," Journal of the American Society of Nephrology, vol. 17, no. 6, pp. 1695-1702, 2006.

[76] J. E. Hall, “The kidney, hypertension, and obesity," Hypertension, vol. 41, no. 3, pp. 625-633, 2003.

[77] K. Rahmouni, M. L. G. Correia, W. G. Haynes, and A. L. Mark, "Obesity-associated hypertension: new insights into mechanisms," Hypertension, vol. 45, no. 1, pp. 9-14, 2005.

[78] G. L. Bakris and E. Ritz, "The message for World Kidney Day 2009: hypertension and kidney disease: a marriage that should be prevented," Kidney International, vol. 75, no. 5, pp. 449-452, 2009.

[79] R. J. Johnson, D.-H. Kang, D. Feig et al., "Is there a pathogenetic role for uric acid in hypertension and cardiovascular and renal disease?” Hypertension, vol. 41, no. 6, pp. 1183-1190, 2003.

[80] P. Habbu, M. Sugoor, and B. Kale, "Serum inorganic phosphorus Level along with serum potassium as a best marker in the diagnosis and prognosis of Chronic Kidney Disease (CKD)," Journal of Chemical, Biological and Physical Sciences A, vol. 4, no. 2, pp. 1922-1926, 2014.

[81] H. J. Adrogué and N. E. Madias, "Sodium and potassium in the pathogenesis of hypertension," The New England Journal of Medicine, vol. 356, no. 19, pp. 1966-1978, 2007.

[82] I. Drenjančević-Perić, B. Jelaković, J. H. Lombard, M. P. Kunert, A. Kibel, and M. Gros, "High-salt diet and hypertension: focus on the renin-angiotensin system," Kidney and Blood Pressure Research, vol. 34, no. 1, pp. 1-11, 2011.

[83] J. F. Baker, E. Krishnan, L. Chen, and H. R. Schumacher, "Serum uric acid and cardiovascular disease: recent developments, and where do they leave us?" The American Journal of Medicine, vol. 118, no. 8, pp. 816-826, 2005.

[84] P. B. Mellen, A. J. Bleyer, T. P. Erlinger et al., "Serum uric acid predicts incident hypertension in a biethnic cohort: the Atherosclerosis Risk in Communities study," Hypertension, vol. 48, no. 6, pp. 1037-1042, 2006.

[85] X. Zhou, L. Matavelli, and E. D. Frohlich, "Uric acid: its relationship to renal hemodynamics and the renal renin-angiotensin system," Current Hypertension Reports, vol. 8, no. 2, pp. 120-124, 2006.

[86] T. S. Perlstein, O. Gumieniak, G. H. Williams et al., "Uric acid and the development of hypertension: the Normative Aging Study," Hypertension, vol. 48, no. 6, pp. 1031-1036, 2006.

[87] R. J. Johnson, M. S. Segal, T. Srinivas et al., "Essential hypertension, progressive renal disease, and uric acid: a pathogenetic link?" Journal of the American Society of Nephrology, vol. 16, no. 7, pp. 1909-1919, 2005.

[88] J. Kanellis and D. H. Kang, "Uric acid as a mediator of endothelial dysfunction, inflammation, and vascular disease," Seminars in Nephrology, vol. 25, no. 1, pp. 39-42, 2005.

[89] D. B. Corry, P. Eslami, K. Yamamoto, M. D. Nyby, H. Makino, and M. L. Tuck, "Uric acid stimulates vascular smooth muscle cell proliferation and oxidative stress via the vascular reninangiotensin system," Journal of Hypertension, vol. 26, no. 2, pp. 269-275, 2008. 


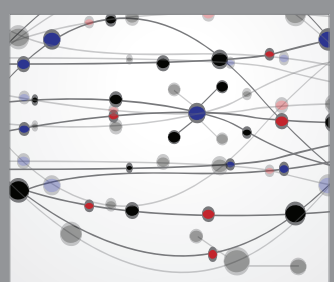

The Scientific World Journal
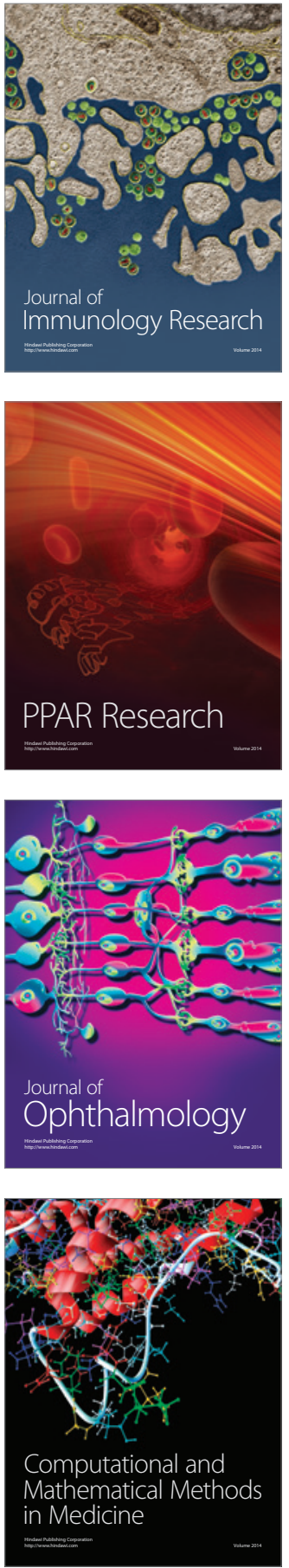

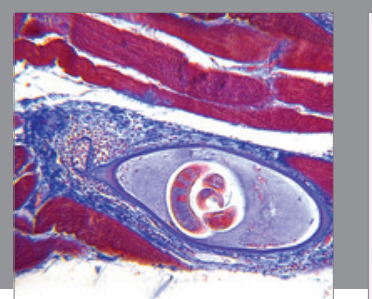

Gastroenterology Research and Practice

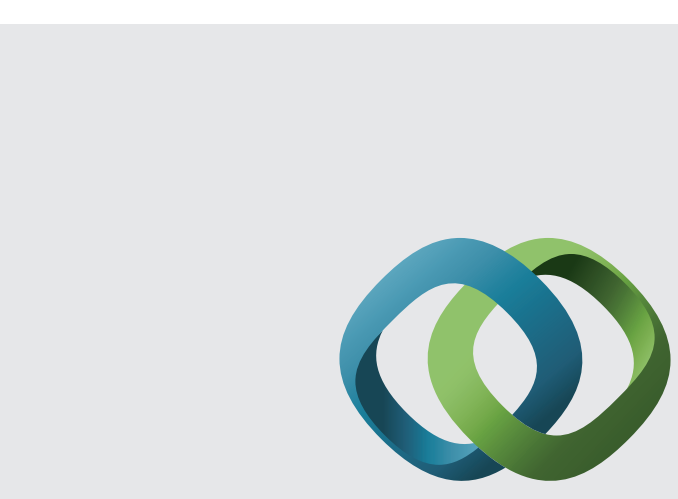

\section{Hindawi}

Submit your manuscripts at

http://www.hindawi.com
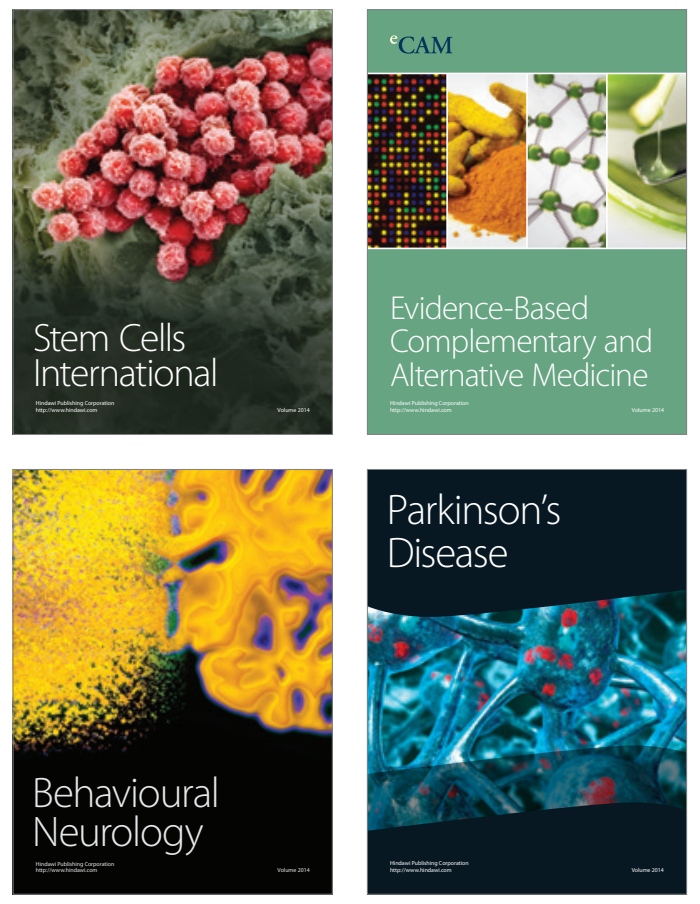
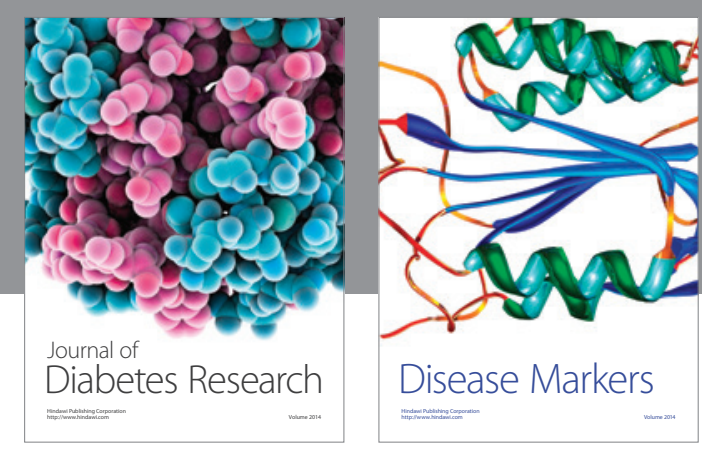

Disease Markers
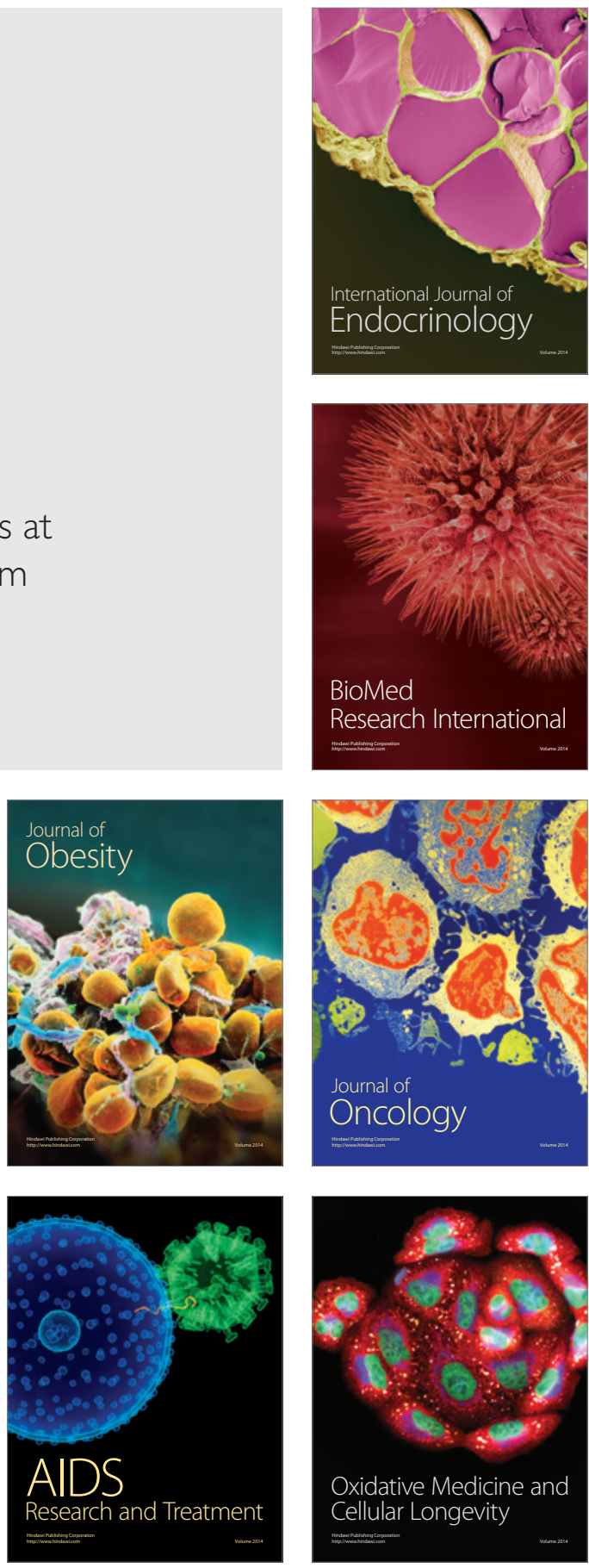